\title{
A pilot study of the reference values for the commoner haematological and biochemical parameters in Saudi nationals
}

\author{
T GILBERT SCOTT*
}

\author{
From the King Abdul Aziz Military Hospital, Tabuk, Saudi Arabia
}

\begin{abstract}
SUMMARY A study of 16 haematological and 24 biochemical parameters in healthy, adult, male, volunteer Saudi blood donors was made, and enabled a preliminary determination of the reference values for these parameters to be made for Saudi Arabia. Statistically significant low means were observed for all the haematological parameters except the mean corpuscular haemoglobin concentration which was raised above Western levels and the mean corpuscular haemoglobin which was normal. A low total leucocyte count was seen to be due largely to a low neutrophil count, but accompanied by a raised lymphocyte count. The main biochemical differences were raised concentrations of serum albumin, alkaline phosphatase, conjugated bilirubin, aspartate aminotransferase, "liver" lactate dehydrogenase and alanine aminotransferase. Decreased concentrations of serum globulin, unconjugated bilirubin and calcium were also found. These changes are discussed in relation to putative endemic disease, ethnic origins and environmental factors.
\end{abstract}

The increasing development of health-care projects in Saudi Arabia, together with an increasing referral rate of sick Saudi nationals to European centres of medical excellence, has prompted the present attempt to define the reference values for the commoner haematological and biochemical parameters. A preliminary study ${ }^{1}$ on inpatients and outpatients in this hospital suggested that there are several parameters which show statistically significant departures from the reference values published in Europe and North America.

Because the results of that study could have been explained in part by pathological bias it was decided to repeat the investigation on a nominally healthy population. Blood donors were chosen for this study in preference to volunteers with whom there might well have been linguistic and other difficulties involved in the collection of the samples. The results reported here thus reflect the values found in apparently healthy, adult, male soldiers and airmen in the approximate age range of 20 to $45 \mathrm{yr}$. Values for women and children can perhaps be derived with reasonable accuracy by using accepted Western male: female and adult:child ratios.

\footnotetext{
*Present address: Department of Pathology Al-Huwaylat Hospital, Al Jubayl, Saudi Arabia.
}

Accepted for publication 4 June 1981
It is hoped that this pilot study will provide suitable guidelines for clinicians practising in those Western countries to which Saudis may be referred as well as a stimulus for a more definitive, wideranging study across the Kingdom of Saudi Arabia itself.

\section{Material and methods}

Whole blood $(10 \mathrm{ml})$ was taken from each donor into dry "vacutainers" at the end of the venesection procedure and the serum separated within one hour and stored at $4^{\circ} \mathrm{C}$ until assayed (usually within four hours, maximally within $24 \mathrm{~h}$ ). For the haematological parameters an additional $5 \mathrm{ml}$ quantity was also taken into "vacutainers" containing EDTA. All the blood samples were random ones, no account being taken of proximity to meal times. Samples taken during the Muslim fast of Ramadan in July/ August are also included.

\section{HAEMATOLOGICAL DATA}

Haemoglobin, haematocrit, erythrocyte count and the indices were studied together with the total leucocyte count and sedimentation rate (Wintrobe method) (ERS). The blood was diluted in a Coulter Diluter III, and the red and white cells counted in a Coulter Counter ZBI; haemoglobin was estimated in 
a Coulter Haemoglobinometer and the haematocrit on an Adams "Autocrit." Blood smears were made in the usual manner and stained either manually or on an Ames "Hema-tek" Slide Stainer. The differential counts were made on the basis of 100 leucocytes in each case.

Quality control checks were made daily using Dade $\mathrm{CH}-60$ cell suspensions and the results observed to lie within the range of \pm 2 SD of the published value.

In this paper the reference values for Western populations have been taken from Dacie and Lewis. $^{2}$

\section{BIOCHEMICAL DATA}

The 24 biochemical parameters studied were all assayed on a DuPont ACA at $37^{\circ} \mathrm{C}$. Quality control checks were kept daily using Dade "Monitrol" sera, all values for these were within \pm 2 SD of their rated mean on the days on which this study was made. All ACA print-outs showing an error-coding were excluded from the survey. Also excluded were all those values found to lie outside (usually above) 2 SD from the calculated mean for any parameter. This was not uncommon in the case of certain enzymes such as creatine kinase which has been shown in a similar study in Ireland by McCormick ${ }^{3}$ to possess many high-valued "outlyers."

The published Western reference values for the biochemical parameters were ali obtained from the DuPont ACA handbook. ${ }^{4}$ In that publication the reference values were all calculated as 2 SD above and below the mean, and this method was continued here wherever possible (see below) in order to make the comparisons more valid.

It was not possible to assay all parameters in every single blood donor because of insufficient serum. Nor was it possible to utilise every blood donor throughout the entire year of the survey (November 1978 to October 1979), because of shortage of materials. The mean values quoted here are for between 129 and 170 donors for each of the biochemical parameters and for 281 donors for the haematological ones.

\section{REDUCTION OF THE DATA}

Distribution histograms of the values for each parameter were made and, in calculating the reference values, little difficulty was experienced with any parameter with the exception of the differential leucocyte count, "liver" lactate dehydrogenase and the serum iron which showed distinctly skewed distributions. When expressed as percentages of the total leucocyte count this skewness tended to disappear in the case of the neutrophils and the lymphocytes, but persisted somewhat in the case of the monocytes and eosinophils. The final reference values for the neutrophils and lymphocytes which have been adopted here were calculated on the basis of their percentages of the mean total white cell count and then expressed as absolute numbers.

The means and standard deviations of the "liver" lactate dehydrogenase and serum iron were calculated after logarithmic transformation. Three other parameters (alkaline phosphatase, creatine kinase and eosinophil count) showed the usual types of distribution apart from the possession of a tail at the upper end. In these cases the means and ranges were calculated after excluding the $2.5 \%$ highest and lowest values, in conformity with current practice.

\section{Results}

The results of this survey are shown in Table 1 for the haematology and Table 2 for the biochemistry. In 은 each Table the mean value for Saudi nationals is given in column 3 and the finally determined reference ranges are shown in columns 5 .

From these Tables it can be seen that the means of 11 out of 12 haematological and 17 out of the 24 biochemical parameters differ significantly from the published Western means (columns 2).

In addition to the above figures the number of blood donors during the last three years who have shown positive tests for HBsAg (Australia antigen) using "Hepanosticon" (Organon Teknika) was 261 out of a total of 2678 . This gives an overall incidence of $9.7 \%$.

\section{Discussion}

\section{HAEMATOLOG Y}

\section{Erythrocytes}

The mean haemoglobin value of $14.88 \mathrm{~g} / \mathrm{dl}$ for Saudi nationals differs statistically significantly from the published Western mean of $15.75 \mathrm{~g} / \mathrm{dl}$. Since this hospital is at an altitude of 745 metres (nearly 2500 feet) above mean sea level it could be argued that the haemoglobin value ought to be higher, perhaps in the region of $16 \mathrm{~g} / \mathrm{dl}$. Although 745 metres does not seem $N$ very great it is pertinent to recall that it carries an atmospheric $\mathrm{PO}_{2}$ some $8 \%$ below that found at sea level.

That there is indeed a tendency to anaemia endemic in this part of Saudi Arabia (the Northern $O$ Hijaz) is borne out by the low mean haematocrit $\mathbb{D}$ with also differs significantly from the mean Western value (see Table 1). Since the total erythrocyte count is also low the tendency to anaemia is due to a $\frac{\mathrm{O}}{\mathbb{D}}$ decrease in total red cell mass rather than in haemoglobin alone. Further evidence for this is given by $\mathbb{Q}$ the significantly higher mean corpuscular haemoglo- 
Table 1 Haematology

\begin{tabular}{|c|c|c|c|c|c|}
\hline Parameter & Western mean & Saudi mean & $\begin{array}{l}\text { Significance of the } \\
\text { difference }(p)\end{array}$ & Saudi range & Units \\
\hline $\begin{array}{l}\text { Haemoglobin } \\
\text { Haematocrit } \\
\text { Red blood cells } \\
\text { Mean corpuscular haemoglobin } \\
\text { concentration } \\
\text { Mean corpuscular haemoglobin } \\
\text { Mean cell volume } \\
\text { White blood cells } \\
\text { Neutrophils Total } \\
\% \\
\text { Lymphocytes Total } \\
\% \\
\text { Monocytes Total } \\
\% \\
\text { Eosinophils Total } \\
\% \\
\text { Eosinophils* Total } \\
\% \\
\text { ESR }\end{array}$ & $\begin{array}{l}15 \cdot 75 \\
0 \cdot 47 \\
5 \cdot 5 \\
\\
32 \cdot 5 \\
29 \cdot 5 \\
86 \\
7000 \\
5000 \\
57 \cdot 5 \\
2500 \\
35 \\
500 \\
6 \cdot 0 \\
240 \\
3 \cdot 5 \\
240 \\
3 \cdot 5 \\
4 \cdot 5\end{array}$ & $\begin{array}{l}14 \cdot 88 \\
0 \cdot 4422 \\
5 \cdot 04 \\
33 \cdot 69 \\
29 \cdot 87 \\
88 \cdot 7 \\
6043 \\
2538 \\
41 \cdot 82 \\
2900 \\
47 \cdot 92 \\
348 \cdot 6 \\
6 \cdot 16 \\
327 \cdot 3 \\
5 \cdot 64 \\
171 \cdot 3 \\
3 \cdot 67 \\
7 \cdot 45\end{array}$ & $\begin{aligned}< & 0.001 \\
< & 0.001 \\
< & 0.001 \\
& <0.001 \\
& \mathrm{NS} \\
< & 0.001 \\
< & 0.001 \\
< & 0.001 \\
< & 0.001 \\
< & 0.001 \\
< & 0.001 \\
& \mathrm{NS} \\
& \mathrm{NS} \\
< & 0.001 \\
< & 0.001 \\
< & 0.001 \\
& \mathrm{NS} \\
< & 0.001\end{aligned}$ & $\begin{array}{l}12 \cdot 6-17 \cdot 2 \\
0 \cdot 38-0 \cdot 51 \\
3 \cdot 82-6 \cdot 26 \\
\\
30-37 \\
23-37 \\
70-108 \\
1600-10500 \\
1000-4000 \\
17-67 \\
1300-4500 \\
22-74 \\
0 \cdot 750 \\
0-12 \\
0-1000 \\
0-17 \\
0-490 \\
0-10 \\
0-22\end{array}$ & $\begin{array}{l}\mathbf{g} / \mathrm{dl} \\
1 \\
\times 10^{12} / \mathrm{mm}^{3} \\
\% \\
\mathrm{pg} \\
\mu \mathrm{m}^{3} \\
/ \mathrm{mm}^{3} \\
/ \mathrm{mm}^{3} \\
\% \\
/ \mathrm{mm}^{3} \\
\% \\
/ \mathrm{mm}^{3} \\
\% \\
/ \mathrm{mm}^{\circ} \\
\% \\
/ \mathrm{mm}^{3} \\
\% \\
\mathrm{~mm} \text { in } 1 \mathrm{~h}\end{array}$ \\
\hline
\end{tabular}

* Recalculated after exclusion of all counts in excess of $440 / \mathrm{mm}^{3}$.

Conversion: traditional units to SI-1000 cells $/ \mathrm{mm}^{3} \approx 1 \& 10^{\circ} /$.

Table 2 Biochemistry

\begin{tabular}{|c|c|c|c|c|c|}
\hline Parameter & Western mean & Saudi mean & $\begin{array}{l}\text { Significance of the } \\
\text { difference }(p)\end{array}$ & Saudi range & Units \\
\hline Acid phosphatase (150) & 0.4 & 0.362 & NS & $0-0.9$ & IU/I \\
\hline Alkaline phosphatase (170) & $6 \cdot 1$ & $9 \cdot 19$ & $<0.001$ & $3 \cdot 4-14 \cdot 9$ & IU/I \\
\hline Amylase (136) & 43 & $56 \cdot 9$ & $<0.001$ & $12-102$ & IU $/ 1$ \\
\hline Total bilirubin (163) & $12 \cdot 8$ & $11 \cdot 3$ & $<0.001$ & $1 \cdot 71-20 \cdot 5$ & $\mu \mathrm{mol} / 1$ \\
\hline Conjugated bilirubin (159) & $3 \cdot 0$ & $6 \cdot 2$ & $<0.001$ & $0-12$ & $\mu \mathrm{mol} / 1$ \\
\hline Unconjugated bilirubin (159) & $9 \cdot 7$ & $5 \cdot \overline{3}$ & $<0.001$ & $0-10$ & $\mu \mathrm{mol} / 1$ \\
\hline Blood urea nitrogen (151) & $2 \cdot 41$ & $2 \cdot 43$ & NS & $1 \cdot 2-3 \cdot 7$ & $\mathrm{mmol} / \mathrm{l}$ \\
\hline Calcium (142) & $2 \cdot 36$ & $2 \cdot 33$ & $<0.001$ & $2 \cdot 08-2 \cdot 58$ & $\mathrm{mmol} / \mathrm{l}$ \\
\hline Cholesterol (160) & $5 \cdot 2$ & $4 \cdot 6$ & $<0.001$ & $2 \cdot 5-6 \cdot 7$ & $\mathrm{mmol} / \mathrm{l}$ \\
\hline Creatine kinase (138) & 118 & $144 \cdot 0$ & $<0.001$ & 24-264 & IU/I \\
\hline Creatinine (146) & 93 & 92 & NS & $53 \cdot 124$ & $\mu \mathrm{mol} / 1$ \\
\hline Glucose (133) & $5 \cdot 0$ & $5 \cdot 2$ & $<0.05$ & $3 \cdot 3-7 \cdot 1$ & $\mathrm{mmol} / \mathrm{l}$ \\
\hline Aspartate aminotransferase (140) & $20 \cdot 5$ & $28 \cdot 15$ & $<0.001$ & $11-46$ & IU/1 \\
\hline Alanine aminotransferase (134) & $19 \cdot 5$ & $30 \cdot 37$ & $<0.001$ & $0-63$ & IU $/ 1$ \\
\hline \multicolumn{6}{|l|}{ Alphahydroxybutyrate dehydrogenase } \\
\hline (129) & 235 & $241 \cdot 8$ & NS & $144-339$ & IU $/ 1$ \\
\hline Iron $(145)$ & $15 \cdot 8$ & $15 \cdot 7$ & NS & $5 \cdot 0-26 \cdot 4$ & $\mu \mathrm{mol} / \mathrm{l}$ \\
\hline Lactate dehydrogenase (141) & 145 & $157 \cdot 9$ & $<0.001$ & $92-224$ & IU/I \\
\hline "Liver" lactate dehydrogenase (144) & 10 & 15.69 & $<0.001$ & $0-38$ & IU $/ 1$ \\
\hline Total protein (169) & 73 & $70 \cdot 8$ & $<0.001$ & $62-80$ & $\mathbf{g} / 1$ \\
\hline Albumin (167) & 43 & $49 \cdot 8$ & $<0.001$ & $43-57$ & $\mathrm{~g} / 1$ \\
\hline Globulin (167) & 30 & $21 \cdot 4$ & $<0.001$ & $11-32$ & $\mathrm{~g} / 1$ \\
\hline Pseudo-cholinesterase $(68)^{*}$ & $13 \cdot 0$ & $13 \cdot 54$ & NS & $7 \cdot 2-19 \cdot 8$ & IU/1 \\
\hline Triglycerides (114) $\dagger$ & $1 \cdot 30$ & $1 \cdot 22$ & NS & $0-2 \cdot 86$ & $\mathrm{mmol} / \mathrm{l}$ \\
\hline Uric acid (152) & 324 & 358 & $<0.001$ & $214-500$ & $\mu \mathrm{mol} / 1$ \\
\hline
\end{tabular}

Figures in parentheses denote the number of tests made in each case.

*This test was discontinued after six months.

$\dagger$ The zero lower limit of this test is due to the large SD obtained. The lowest value actually recorded was $0 \cdot 27 \mathrm{mmol} / \mathrm{l}$.

bin concentration and mean cell volume and normal mean corpuscular haemoglobin. The presence of normal serum iron concentrations (Table 2) is evidence that there is no endemic nutritional iron deficiency. This tendency to anaemia appears to be of macrocytic, "hyperchromic" type, and although this could be due theoretically to folate or $B_{12}$ subnutrition, it seems more likely that it is secondary to endemic liver disease (see below). It should perhaps be recorded here that the blood donors were all well- paid soldiers and unlikely to suffer from malnutrition, particularly since fresh fruit, vegetables and dairy products are all freely available and relatively inexpensive.

\section{Leucocytes}

The total leucocyte count is significantly low at about $86 \%$ of the Western mean. The difference in neutrophil count is very marked (some $50 \%$ of the Western mean) and the lymphocytes increased, but less 
dramatically, at $116 \%$ of the Western mean. These findings are so whether the results are expressed as percentage figures or as absolute numbers, although the neutrophil change becomes less marked $(73 \%)$ and the lymphocyte change more so $(137 \%)$ when expressed as percentages. These changes could be the result of mild endemic pathology but some preliminary figures (to be published) from an ongoing survey of the same parameters in Westerners resident in this country suggest that some (but not all of them) share these changes, which may therefore be environmental in origin rather than pathological or ethnic.

The monocytes show significant decrease below the Western value when expressed in absolute numbers but a significant increase when expressed as a percentage. The significance of this is not clear. Possibly it may be related to malaria which, although not strictly speaking endemic in the Northern Hijaz, is sometimes seen in military personnel originating in the southern regions where it is more common.

The eosinophils show very great differences from published Western values. Unfortunately the distribution histogram for the eosinophils is so skewed that it is not possible to determine the mean and range with any accuracy, even after a logarithmic trans- formation is made. The histogram also shows an extensive tail to the right. Of the 281 blood donors $26 \%$ had eosinophil counts greater than 400 and $16 \%$ over 600 . The two highest counts in this series were 2400 and $3300 / \mathrm{mm}^{3}\left(2 \cdot 4\right.$ and $\left.3 \cdot 3 \times 10^{9} / 1\right)$. The bulk of this eosinophilia probably reflects asymptomátic parasitism, much of it schistosomiasis. On the other hand, if all eosinophil counts more than $440 / \mathrm{mm}^{3}$ (the upper limit of the Western range) are excluded, the mean eosinophil count of the remainder is significantly lower than in the West (Table 1). The reason for this is not clear, but it is possible that there is less allergy here than in the West.

\section{Biochemistry}

A clearer picture of the biochemical differences between Saudi nationals and the published Western means can be obtained from the Figure in which the $\mathrm{O}$ parameters are ranked in order of decreasing difference in SDs from the Western mean. The most outstanding departures are the increase in serum albumin and the decrease in serum globulin which together add up to a small decrease in the total $\overrightarrow{0}$ protein concentrations. As is well known, persistent venous stasis during phlebotomy may raise serum protein concentrations by 10 to $15 \% .^{5}$ In the present
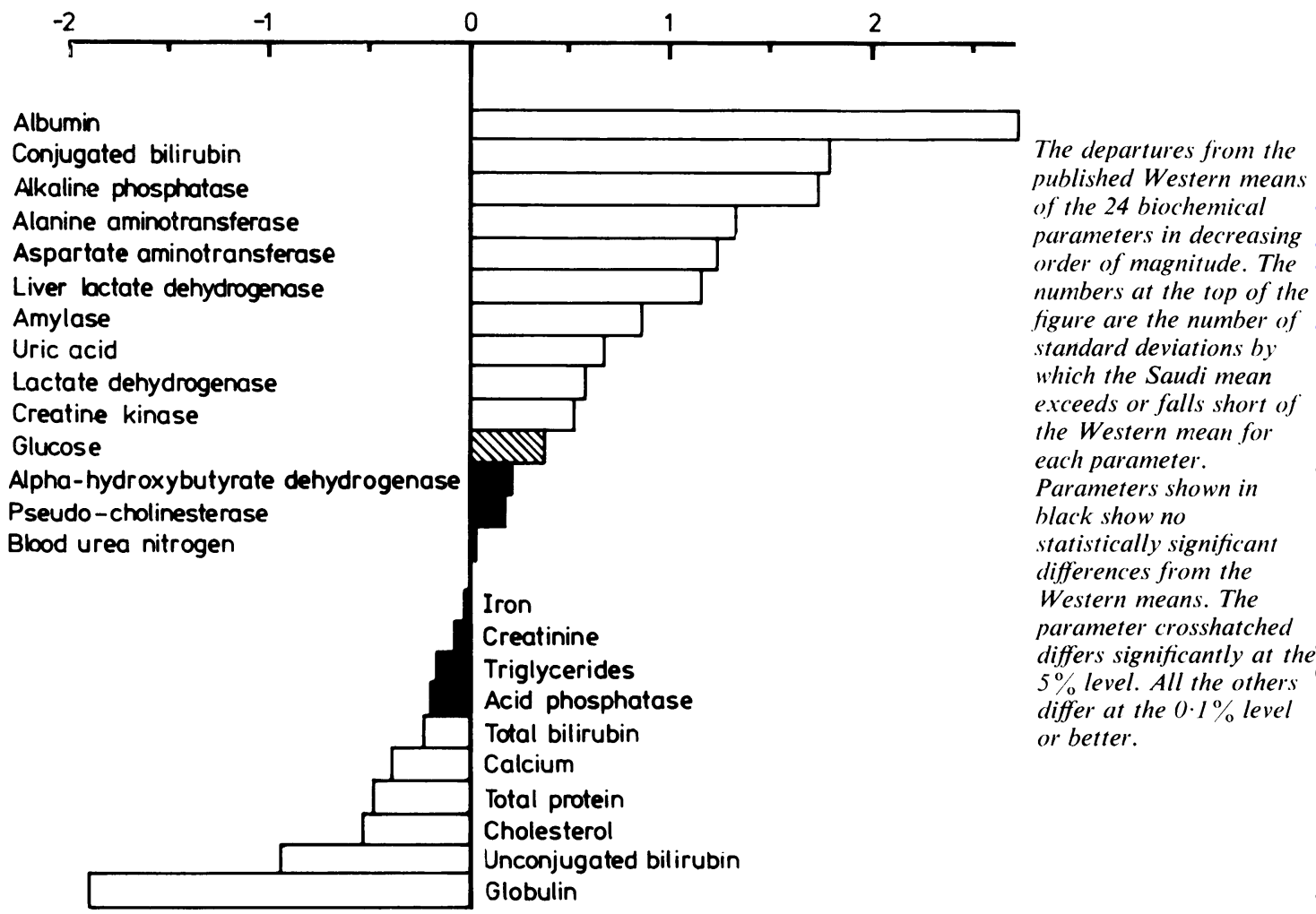

The departures from the published Western means of the 24 biochemical parameters in decreasing order of magnitude. The numbers at the top of the figure are the number of standard deviations by which the Saudi mean exceeds or falls short of the Western mean for each parameter.

Parameters shown in hlack show no statistically significant differences from the Western means. The parameter crosshatched differs significantly at the $5 \%$ level. All the others differ at the $0 \cdot 1 \%$ level or better. 
series total protein was below the Western mean and therefore the change in albumin is probably not due to this artefact.

The increase in albumin is a most unusual and unexpected finding. It is difficult to explain in pathological terms and it seems at first sight that the reason may be ethnic or possibly environmental. A study in expatriate Westerners resident here suggests that the cause is environmental since they also show raised concentrations of serum albumin which are statistically significant. ${ }^{6}$

Other departures from published Western values are a rise in alkaline phosphatase, conjugated bilirubin, aspartate aminotransferase, "liver" lactate dehydrogenase and alanine aminotransferase in decreasing order of magnitude. At the other end of the scale is a decrease in unconjugated bilirubin and calcium. With the exception of these last two substances all the above changes could be explained by assuming that there is a degree of endemic subclinical hepatitis in the "normal" population of Saudi Arabia. Our figure for the incidence of Australia antigen positivity, which is nearly 100 times that reported in United Kingdom blood donors, bears out this suggestion, as does the frequency of hepatitis and cirrhosis (confirmed by liver biopsy) in this hospital. On the other hand it must be conceded that the very low globulin value is against this, particularly cirrhosis.

The significantly lower calcium concentrations could well be of no pathological significance owing to increased protein-binding by the raised serum albumin. Applying a correction to the mean serum calcium value brings it very close to that of the published Western mean. Unfortunately it is not now possible to make this correction with each individual donor.

Statistically significant increases in serum uric acid concentrations were also found. Such findings have been confirmed by Fatani et $a^{7}$ in a study of over 1000 apparently healthy Saudis. This rise may be associated with high protein intake for which, however, there is only anecdotal evidence. Alternatively it may be associated with increased tissue breakdown in the harsher environment of this country, but again this view is entirely speculative at present. A study of the uric acid concentrations of Saudi patients referred to Europe might prove interesting in this regard.

In summary it is possible to say that many of the differences between the mean Saudi values and the published Western ones may prove to be of clinical significance. This is particularly so in the case of the albumin and the globulin concentrations. The means for both of these parameters differ by more than 2 SD from the published Western means and on that account could be regarded as "pathological". It may also prove necessary to be cautious in interpreting the clinical laboratory results in Saudi patients for many of the other parameters described here and not only in the albumin and globulin concentrations.

\section{References}

${ }^{1}$ Scott TG. A preliminary study of the normal values and ranges for various haematological biochemical parameters in Saudi nationals. Proceedings of the Fourth Saudi Medical Conference, Dammam, 1979.

2 Dacie JV, Lewis SM. Practical haematology. 4th ed. London: Churchill, 1968.

${ }^{3}$ McCormick D. The normal range for serum creatine phosphokinase. Ir J Med Sci 1976;145:86-91.

4 DuPont Corporation. Test methods on the ACA. Wilmington: DuPont, 1978.

${ }^{5}$ Baron DN. A short textbook of chemical pathology. London: English Universities Press, 1973: S4.

- Scott TG. Some biochemical and haematological changes found in expatriate Western males resident in Tabuk, Saudi Arabia (in press).

${ }^{7}$ Fatani H, Shobokshi D, Baig HI. Uric acid levels and hyperuricaemia in the Western region of Saudi Arabia. Proceedings of the Sixth Saudi Medical Conference, Jeddah, 1981.

Requests for reprints to: Dr TG Scott, Department of Pathology, Al-Huwaylat Hospital, Al Jubayl, Saudi Arabia. 